\title{
Calcite surface structure and reactivity: molecular dynamics simulations and macroscopic surface modelling of the calcite-water interface $\dagger$
}

\author{
M. Wolthers, ${ }^{a b}$ D. Di Tommaso, ${ }^{b}$ Z. Du ${ }^{b}$ and N. H. de Leeuw ${ }^{b}$ \\ Received 5th July 2012, Accepted 18th September 2012 \\ DOI: $10.1039 / \mathrm{c} 2 \mathrm{cp} 42290 \mathrm{e}$
}

Calcite-water interactions are important not only in carbon sequestration and the global carbon cycle, but also in contaminant behaviour in calcite-bearing host rock and in many industrial applications. Here we quantify the effect of variations in surface structure on calcite surface reactivity. Firstly, we employ classical Molecular Dynamics simulations of calcite surfaces containing an etch pit and a growth terrace, to show that the local environment in water around structurally different surface sites is distinct. In addition to observing the expected formation of more calcium-water interactions and hydrogen-bonds at lower-coordinated sites, we also observed subtle differences in hydrogen bonding around acute versus obtuse edges and corners. We subsequently used this information to refine the protonation constants for the calcite surface sites, according to the Charge Distribution MUltiSite Ion Complexation (CD-MUSIC) approach. The subtle differences in hydrogen bonding translate into markedly different charging behaviour versus $\mathrm{pH}$, in particular for acute versus obtuse corner sites. The results show quantitatively that calcite surface reactivity is directly related to surface topography. The information obtained in this study is not only crucial for the improvement of existing macroscopic surface models of the reactivity of calcite towards contaminants, but also improves our atomic-level understanding of mineral-water interactions.

\section{Introduction}

Calcite is one of the most abundant minerals in the Earth's surface environment. It is one of the main biominerals ${ }^{2}$ and of fundamental importance as a regulator of the chemistry of aquatic environments, ${ }^{3}$ as a recorder of palaeo-environmental conditions, ${ }^{4}$ scavenger of trace metals ${ }^{5}$ and as a long-term sink for carbon. ${ }^{6}$ Calcite precipitation directly from solution and through mineral carbonation is currently one of the most viable routes for carbon sequestration. ${ }^{7-9}$ The key issue in efficient and directed calcite precipitation, and in determining the long-term stability of calcite-trapped $\mathrm{CO}_{2}$ and trace metals is a fundamental understanding of the mineral surface processes controlling crystal growth ${ }^{9-12}$ and dissolution. ${ }^{13,14}$

In order to understand and describe the reactivity of the calcite mineral surface, several surface models have been developed over

\footnotetext{
${ }^{a}$ Department of Earth Sciences, Utrecht University, P.O. Box 80021, 3508 TA Utrecht, The Netherlands.E-mail:m.wolthers@uu.nl

${ }^{b}$ Department of Chemistry, University College London, 20 Gordon Street, London WC1 HOAJ, UK

$\dagger$ Electronic supplementary information (ESI) available: Potential energy and volume of a box of 2028 water molecules (Fig. S1); potential energy of the calcite slab plus water over the course of a production (Fig. S2); potential parameters used in this work (Table S1); distribution of HBs around surface calcium (Table S2) and carbonate (Table S3) sites for three different temperatures. See DOI: $10.1039 / \mathrm{c} 2 \mathrm{cp} 42290 \mathrm{e}$
}

the last few decades. ${ }^{15-21}$ In recently developed models that follow the CD-MUSIC approach, ${ }^{1,22}$ the proton affinity of a reactive surface group is related to the bond lengths within this group and the number of hydrogen-bonds (H-bonds) between the surface group and the solution. Currently, these models rely on bond-length analyses of average surface sites ${ }^{23-25}$ where the average number of $\mathrm{H}$-bonds was obtained by fitting to experimental surface potential data. ${ }^{19}$ Even though this calcite surface chemical model is in agreement with calcite surface potential data, it does not capture the differential reactivity of sites in acute or obtuse step edges observed experimentally, ${ }^{26}$ nor does it predict different behaviour for step or kink sites known to play a crucial role during calcite growth, ${ }^{10,11}$ dissolution $^{14}$ and interaction with (in)organic compounds. ${ }^{27}$ Clearly, a surface chemical model for calcite that can describe this behaviour needs detailed information on the variation in bond lengths, in particular the bond between surface calcium and its coordinating water molecules that together form the $\equiv \mathrm{Ca}\left(\mathrm{OH}_{2}\right)_{n}$ surface group (with $\equiv$ indicating surface site and $n=1$ in previous models ${ }^{19,21}$ ), and $\mathrm{H}$-bonds for structurally different surface sites. Thus far, such detailed site-specific information can only be obtained from computer simulation techniques.

The calcite surface has been the subject of numerous simulation studies. ${ }^{25-53}$ In particular, these studies focused on simulations of the flat or stepped (1014) surface, which is 


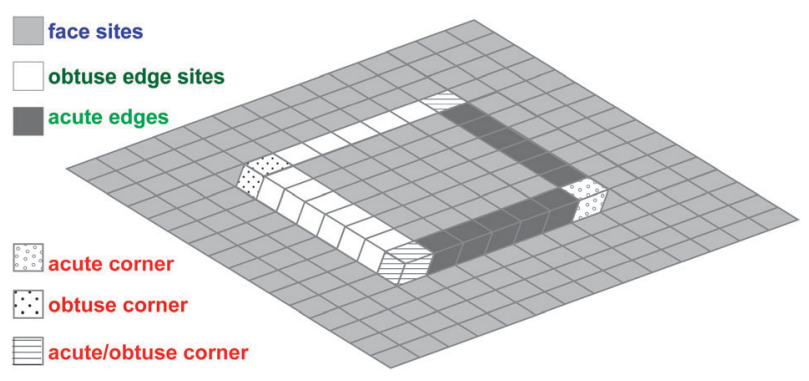

Fig. 1 Sketch of a terrace on the calcite (1014) face to indicate the position of face site, acute and obtuse edge sites, and different types of corner sites.

the dominant face exposed on cleaved, growing and dissolving calcite. ${ }^{54-56}$ Previous simulation studies of stepped and/or defective calcite surfaces have investigated dissolution energies, $34,37,42,57$ kink energies, ${ }^{58}$ and the interaction of water molecules, ${ }^{42,52}$ trace metals $^{34,59}$ and organic compounds ${ }^{27,41,45,53,60}$ with steps and defects. Perry et al. ${ }^{39}$ reported an average of two hydrogen-bonds for water molecules in the first water layer near the atomically flat calcite surface, with water molecules at a distance between 1.7 to $2.5 \AA$ from the surface, experiencing a mixture of one, two, and three hydrogen-bonds. Lardge et al. ${ }^{51}$ used Density Functional Theory (DFT) to investigate water adsorption on $\{10 \overline{1} 4\}$ calcite surfaces with steps and vacancies. They found that a single water molecule binds more strongly to acute steps than to obtuse steps. For calcite steps exposed to liquid water, Spagnoli et al. ${ }^{42}$ showed that the water density was significantly greater at the obtuse than at the acute step. The disruption of the surrounding water by the atomically rough surface of the amorphous precursor to calcite has been shown ${ }^{12}$ to enhance its growth in favour of calcite.

While Freeman et al. ${ }^{43}$ recently determined the variation in the number of hydrogen bridges between closely spaced acute and obtuse steps at vicinal surfaces in their study, none of these previous studies reported the actual variation in numbers of hydrogen-bonds around structurally different sites (face versus edge and corner sites, Fig. 1), nor the variation in distance between distinct surface calcium sites and its nearest water molecule. Such information is crucial for the refinement of CD-MUSIC type surface chemical models and is therefore reported here. The information on the difference in water structure around these sites is subsequently used to quantify the protonation constants for the structurally different surface groups following the CD-MUSIC formalism. This shows that subtle differences in the interaction of various sites with water molecules translate into significantly different charging behaviour, in particular for the acute versus obtuse corner (kink) sites. Implications for proton affinity constants and calcite surface reactivity towards calcium, (bi-)carbonate and contaminants are discussed.

\section{Theoretical methods}

The interaction of liquid water with the heterogeneous calcite surface was investigated using classical molecular dynamics simulations. These methods are based on the Born model of solids ${ }^{61}$ which assumes that the ions in the crystal interact via long-range electrostatic forces and short-range forces, including both the repulsions and the Van der Waals' attractions between neighbouring electron charge clouds, and, where appropriate, angle-dependent forces to allow for directionality of bonding as, for example, in the covalent carbonate anion. ${ }^{62}$ The electronic polarizability of the ions is included via the shell model of Dick and Overhauser ${ }^{63}$ in which each polarizable ion, in the present case the oxygen ion, is represented by a core and a massless shell, connected by a spring. The polarizability of the model ion is then determined by the spring constant and the charges of the core and shell. We assigned the oxygen shell a small mass of 0.2 a.u., ${ }^{64,65}$ which is small compared to the mass of the hydrogen atom of 1.0 a.u., which ensured that there would be no exchange of energy between vibrations of oxygen core and shell with oxygen and hydrogen vibrations. ${ }^{66}$ However, due to the small shell mass, we needed to run the MD simulation with a small timestep of $0.2 \mathrm{fs}$ in order to keep the system stable.

The computer code used for the molecular dynamics simulations was DL_POLY $2.20 .^{67}$ In the DL_POLY code, the integration algorithms are based around the Verlet leap-frog scheme ${ }^{68}$ and we have used the Nosé-Hoover algorithm ${ }^{69,70}$ for the thermostat. The Nosé-Hoover parameters were set at 0.5 ps for both the thermostat and barostat relaxation times.

We simulated a repeating calcite slab, containing $840 \mathrm{CaCO}_{3}$ units, with a growth island of $16 \mathrm{CaCO}_{3}$ units on one side and an etch pit of the same size on the other side of the slab (Fig. 2). The initial $22 \AA$ gap between the repeating slabs was filled with 2048 water molecules, and the simulation cell contained 14912 species including shells.

The simulation cell was equilibrated at NPT (constant number of particles, pressure and temperature), at $P=1$ atm and $300 \mathrm{~K}, 320 \mathrm{~K}$ and $340 \mathrm{~K}$ for 140 ps after which the statistics were collected for at least another nanosecond at each temperature. To test if the $22 \AA$ gap was wide enough to preclude interactions between the calcite surfaces, we additionally simulated the system with a gap of $28 \AA$ distance, filled with 2560 water molecules. After 140 ps equilibration and 60 ps data collection in NPT, we observed no effect of gap size on the radial distribution function for oxygen in the water molecules with oxygen and hydrogen in neighbouring water molecules or on the hydration energy. To test for strain in the simulation cell with the $22 \AA$ gap, we ran the final configuration of the NPT production using the NoT (constant number of particles, stress and temperature; 20 ps equilibration) ensemble, but no significant change in lattice vectors or angles was observed.

\section{Potential model}

Calcite has a rhombohedral crystal structure with space group $R \overline{3} c$ and $a=b=4.990 \AA, c=17.061 \AA, \alpha=\beta=90^{\circ}$ and $\gamma=120^{\circ} .{ }^{71}$ In order to simulate the structure, we have used the parameters for the short-range interactions in calcite derived empirically by Pavese et al., ${ }^{62}$ who reported very good agreement between their simulated and the experimental thermal dependence of structural and elastic properties of calcite. At the end of the production run in NPT, our calcite was calculated to have lattice parameters of $a=b=4.80 \pm 0.14 \AA, c=17.63 \pm$ $0.17 \AA, \alpha=\beta=90.00 \pm 1.72^{\circ}$ and $\gamma=119.81 \pm 2.14^{\circ}$. Although Pavese et al.'s potential model was fitted to bulk 


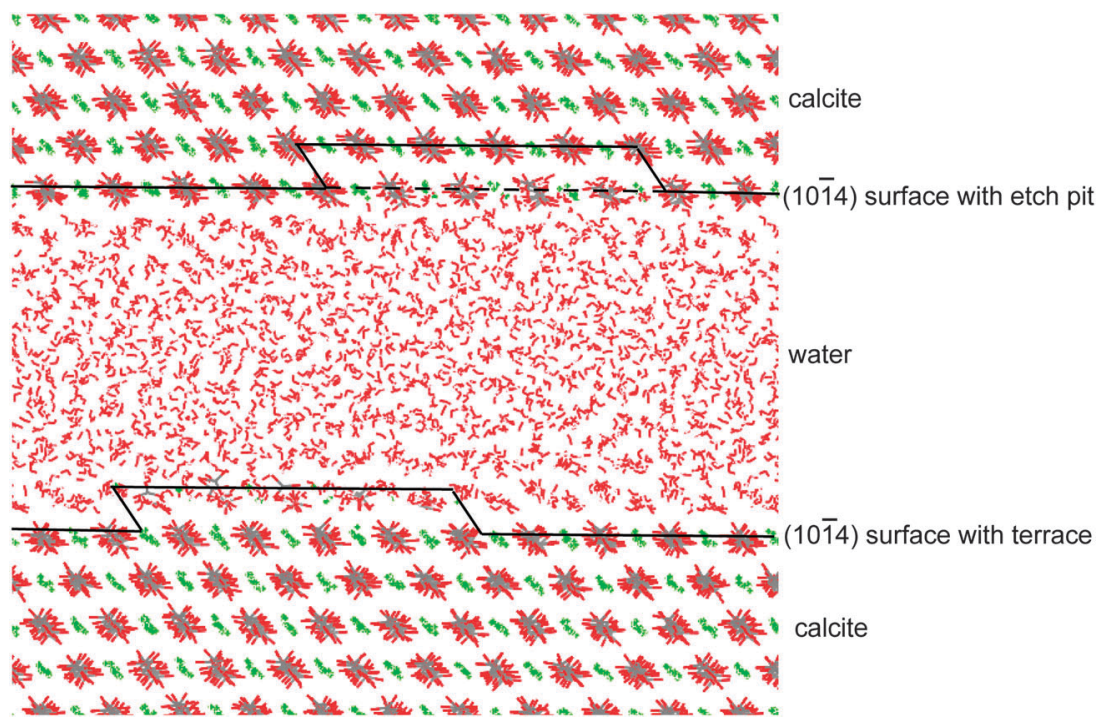

Fig. 2 Water layer between the calcite slabs; one slab with a terrace and the other with an etch pit. Black lines indicate surface topography; calcium indicated in green, oxygen in red, carbon in grey and hydrogen in white.

properties, it is generally possible for ionic materials to transfer potential parameters to surface calculations. In ionic materials after relaxation, the Madelung potentials are $90 \%$ or more of the bulk values and, hence, the change of ionic radii is negligible. In addition, it has been shown in a previous study of the surface structures and stabilities of three calcium carbonate polymorphs, namely calcite, aragonite and vaterite, that the potential model derived by Pavese et al. ${ }^{62}$ for calcite is directly transferable to different calcium carbonate phases, accurately reproducing the experimental morphologies of all three polymorphs. ${ }^{29}$

The potential parameters used for the intra- and intermolecular water interactions are those described in a previous paper of MD simulations on $\mathrm{MgO}$ surfaces. ${ }^{30}$ For the interactions between water molecules and calcite surfaces, we have used the potential parameters previously fitted to calcite ${ }^{29}$ and successfully used in MD simulations of water adsorption at point defects and crystal dissolution from calcite steps. ${ }^{57,72}$ These potential parameters reproduce the experimental heat of formation of calcite from its aqueous ions to an acceptable degree of accuracy (within $20 \mathrm{~kJ} \mathrm{~mol}^{-1}$ ), even though the parameters were not fitted to this process. Table $\mathrm{S} 1$ in the ESI $\dagger$ lists the parameters of the complete potential model used in this simulation study. Further evaluation of the potential parameters used is given in the next section.

\section{Car-Parrinello MD method}

Car-Parrinello molecular dynamics (CP-MD) simulations of a $\mathrm{Ca}^{2+}$ and $\mathrm{CaCO}_{3}$ in water were carried out using the $\mathrm{CP}$ code included in the Quantum-ESPRESSO package, versions 3.2 and 4.0.1. ${ }^{73}$ The Perdew-Burke-Ernzerhof (PBE) gradient corrected functional ${ }^{74}$ was applied along with the Vanderbilt ultrasoft pseudopotentials (USPP). ${ }^{75}$ The electronic wavefunctions were expanded in a plane wave basis set with a kinetic energy cut-off of $30 \mathrm{Ry}$. The USPP for C was taken from the standard Quantum-ESPRESSO distribution, whereas the USPP for O and $\mathrm{H}$ were generated using the USPP 7.3 pseudopotential program with a scalar-relativistic calculation. ${ }^{76}$ The time step for simulations was set to $0.12 \mathrm{fs}$ and the electronic mass was set to 600 a.u. All simulations were carried out in the NVT ensemble using a Nosé-Hoover chain thermostat ${ }^{77}$ to maintain the average temperature at $T=400 \mathrm{~K}$, which is necessary to obtain a liquid-like water structure and diffusion time scales when using gradient corrected density functionals. ${ }^{78}$ The isotopic mass of deuterium (D) was used for hydrogen. The simulations of one $\mathrm{Ca}^{2+}$ and one $\mathrm{CO}_{3}{ }^{2-}$ were conducted in a cubic cell of $L=11.94 \AA$ containing 52 water molecules, and the simulations of one $\mathrm{CaCO}_{3}$ unit were conducted in a cubic cell of $L=11.94 \AA$ containing 53 water molecules. After 2 ps of equilibration, the statistics were collected for $\sim 18$ ps.

\section{Validation of the classical MD simulations}

The polarizable shell-model water potential used in the present study has been specifically developed to simulate liquid water-solid interfaces. While more recently developed calcitewater interface MD methods ${ }^{12,46,47}$ were proven successful for simulating calcium carbonate nucleation and growth, the interfacial-water structure is better described by the potential model used in the current study, as compared to experimental data (Table 1) and with ab initio results on the distance between water molecules and a calcium ion (Fig. 3). Moreover, simulations of the type presented in the present work would not be achievable using ab initio methods due to the sheer size required for the simulated calcite system. Therefore, the polarizable shell-model water potential ${ }^{30}$ was used in the current study. However, this potential has been shown previously to undergo a phase change at $300 \mathrm{~K}$ within $\sim 1 \mathrm{~ns}^{40,79}$ in NPT production runs with small systems (up to 860 water molecules). We therefore carefully re-evaluated the potential model for a water box of a similar size to the water layer between the calcite slabs (2028 water molecules). After 3 ns production at $260 \mathrm{~K}, 280 \mathrm{~K}, 300 \mathrm{~K}, 320 \mathrm{~K}, 340 \mathrm{~K}$ and $400 \mathrm{~K}$ in NPT, we observed a similar phase change only at the lowest two temperatures tested (Fig. S1, ESI $\dagger$ ). This phase change 
Table 1 Local environment of calcium surface sites at structurally different positions in the (1014) surface: Distance at which the highest density of nearest oxygen in the water is found, and the number of oxygen atoms $\left(n_{\mathrm{O}_{\mathrm{w}}}\right)$ in this shell. $\equiv$ indicates a surface group; $\mathrm{LW}=$ liquid water; $\mathrm{ML}=$ monolayer coverage

\begin{tabular}{|c|c|c|}
\hline$\equiv \mathrm{Ca}$ site position, this study & $\equiv \mathrm{Ca}-\mathrm{O}_{\text {water }}(\AA)$ & $n_{\mathrm{O}_{\mathrm{w}}}$ \\
\hline Face & 2.435 & $0.99-1.15$ \\
\hline Acute edge, growth island & 2.475 & 1.99 \\
\hline Acute edge, etch pit & 2.445 & 2.01 \\
\hline Obtuse edges & 2.435 & $1.77-1.96$ \\
\hline Acute corners, growth island & 2.445 & 3.06 \\
\hline Obtuse corners, growth island & 2.435 & 3.06 \\
\hline Corners, etch pit & 2.475 & 1.01 \\
\hline$\equiv \mathrm{Ca}-\mathrm{O}_{\text {water }}$ previously published & $\equiv \mathrm{Ca}-\mathrm{O}_{\text {water }}(\AA)$ & $n_{\mathrm{H}_{2} \mathrm{O}^{*}}$ \\
\hline Classical MD simulation $^{29}$ & 2.4 & $<\mathrm{ML}$ \\
\hline Classical MD simulation $^{32}$ & 2.55 & ML \\
\hline Classical MD simulation $^{37}$ & 2.45 & ML \\
\hline Classical MD simulation ${ }^{40}$ & 2.2 & LW \\
\hline Classical MD simulation ${ }^{44}$ & 2.2 & LW \\
\hline Classical MD simulation $^{39}$ & 2.3 & LW \\
\hline$a b$ initio simulation ${ }^{50}$ & 2.46 & $<\mathrm{ML}$ \\
\hline \multirow[t]{3}{*}{$a b$ initio simulation ${ }^{51}$} & 2.47 (face) & \\
\hline & 2.53 (obtuse edge) & 1 \\
\hline & 2.65 (acute edge) & 1 \\
\hline Classical MD simulation $^{46}$ & 2.0 & LW \\
\hline Classical MD simulation $^{47}$ & $\sim 2.3$ & LW \\
\hline \multicolumn{3}{|l|}{$\mathrm{O}_{\text {water }}$ distance $\perp$ to $(10 \overline{1} 4)$} \\
\hline$\equiv$ Ca-coordinated water, this study & $2.41(2.35-2.43)$ & \\
\hline$\equiv$ Ca-coordinated water, surface diffraction ${ }^{24}$ & $2.35 \pm 0.05$ & \\
\hline$\equiv$ Ca-coordinated water, X-ray scattering ${ }^{22}$ & $2.3 \pm 0.1$ & \\
\hline$\equiv$ Ca-coordinated water, $\mathrm{X}$-ray scattering ${ }^{25}$ & $2.50 \pm 0.12$ & \\
\hline
\end{tabular}

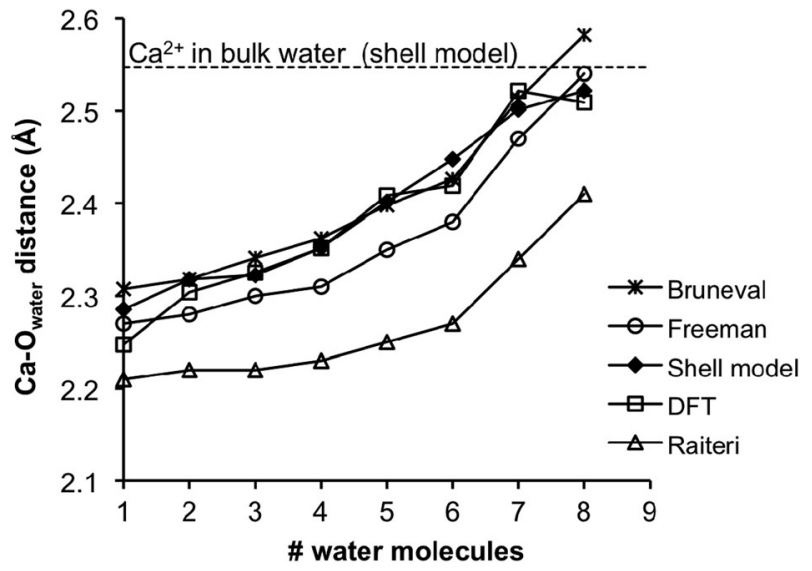

Fig. 3 Distance between $\mathrm{Ca}^{2+}$ and oxygen in water molecule versus number of water molecules. Shell model results $(\bullet$, dashed line) were obtained using the potential listed in Table S1 (ESI $\dagger$ ); ( $\square$ ) Density Functional Theory results; ${ }^{84}$ other results were previously obtained by Raiteri et al.: ${ }^{46}$ molecular dynamic simulations using $(*)$ polarizable potential $(\mathrm{SWM} 4-\mathrm{NDP}){ }^{96}(\bigcirc)$ polarizable potential model $;{ }^{97}(\triangle)$ Raiteri force field. ${ }^{46}$

coincides with a sudden decrease in potential energy and increase in density, and a steady drop in the 3D diffusion coefficients towards zero. After the phase change, strong ordering of the water molecules is observed and the system is stable for the remainder of the production run $(\sim 2.5 \mathrm{~ns})$. At the other temperatures for bulk water and the calcite-water configuration, no such phase change is observed for the entire production run (Fig. S1 and S2, ESI $\dagger$ ). The bulk water density is similar to previously reported values for shell model water $^{29,30,40}$ (Fig. S1B, ESI $\dagger$ ) and bulk-water 3D diffusion coefficients are $\sim 2.9 \mathrm{~m}^{2} \mathrm{~s}^{-1}$ at $400 \mathrm{~K}$ and $\sim 1.6 \mathrm{~m}^{2} \mathrm{~s}^{-1}$ at $340 \mathrm{~K}$, compared to the experimental value of $2.3 \mathrm{~m}^{2} \mathrm{~s}^{-1}$ at $300 \mathrm{~K}^{80,81}$

Since our main aim was to investigate the water structure at the calcite-water interface, we also carefully evaluated the structure of our bulk water; of water around a calcium ion; and around a calcium-carbonate complex. The number of $\mathrm{H}$-bonds obtained for our bulk water (3.8) compares well with the average number of $\mathrm{H}$-bonds obtained from simulations of water using ab initio ( $n_{\mathrm{HB}}=3.3$ to 3.8 depending on the level of theory) or other water potentials like the TIP3P $\left(n_{\mathrm{HB}}=3.7\right)$ or the extended simple point charge $(\mathrm{SCP} / \mathrm{E})$ potentials $\left(n_{\mathrm{HB}}=3.5^{82}\right)$ (Table 2$)$. The average $\mathrm{O}_{\mathrm{W}}-\mathrm{O}_{\mathrm{W}}$ distance in our bulk water is $2.975 \AA$, independent of $T$. This value is very close to the experimental value of $2.976 \AA$ using microwave spectra. ${ }^{83}$ The number of $\mathrm{H}$-bonds between water in the hydration shell of calcium and the surrounding water molecules also agrees with our ab initio results (Table 2). Moreover, the distance between the calcium ion and one to eight water molecules (NVT) results is identical to DFT results ${ }^{84}$ (Fig. 3). Considering the calcium carbonate complex in water, there are approximately 1.5 times as many $\mathrm{H}$-bonds with carbonate oxygen than observed in our DFT calculations (Table 3). However, it remains unresolved whether the polarizable shell model overestimates the number of H-bonds or whether DFT methods based on generalized gradient approximations (like the Perdew-Burke-Ernzerhof or PBE gradient) underestimate this number, due to the well-known delocalization of electron charge. Note that the reported hydration energy of the carbonate ion of $-1301 \pm 2 \mathrm{~kJ} \mathrm{~mol}^{-1},{ }^{46}$ as calculated using 
Table 2 Distribution of the number of hydrogen-bonds for the water molecules coordinated to the different calcium surfaces, free calcium or water oxygen. Temperature is $300 \mathrm{~K}$ unless otherwise stated. The values given are percentages of molecules with the given number of hydrogenbonds ${ }^{82}$

\begin{tabular}{|c|c|c|c|c|c|c|c|c|}
\hline \multirow[b]{2}{*}{$\equiv \mathrm{Ca}$ site position } & \multicolumn{7}{|c|}{ Number of hydrogen-bonds } & \multirow[b]{2}{*}{ Average $^{c}$} \\
\hline & $0(\%)$ & $1(\%)$ & $2(\%)$ & $3(\%)$ & $4(\%)$ & $5(\%)$ & $6(\%)$ & \\
\hline face site & 2.2 & 19.8 & 42.7 & 27.4 & 7.1 & 0.8 & 0.1 & 2.20 \\
\hline acute edge site & 3.1 & 23.6 & 39.2 & 24.6 & 7.9 & 1.5 & 0.2 & 2.16 \\
\hline obtuse edge site & 2.1 & 17.4 & 42.2 & 28.1 & 8.9 & 1.2 & 0.1 & 2.28 \\
\hline acute corner site & 2.2 & 19.8 & 42.7 & 27.4 & 7.1 & 0.8 & 0.1 & 2.20 \\
\hline $\begin{array}{l}\text { obtuse corner site } \\
\mathrm{Ca}^{2+} \text { in water }\end{array}$ & 3.9 & 23.6 & 39.1 & 24.3 & 7.8 & 1.1 & 0.2 & 2.13 \\
\hline$T=300 \mathrm{~K}$ (shell model) & 1.1 & 12.0 & 45.4 & 29.5 & 10.0 & 2.0 & 0.1 & 2.42 \\
\hline$T=320 \mathrm{~K}$ (shell model) & 1.2 & 15.4 & 44.6 & 28.2 & 9.0 & 1.5 & 0.1 & 2.34 \\
\hline$T=340 \mathrm{~K}$ (shell model) & 1.1 & 16.7 & 42.4 & 28.3 & 9.3 & 2.3 & 0.0 & 2.35 \\
\hline$T=400 \mathrm{~K}$ (shell model) & 2.6 & 20.4 & 46.6 & 23.3 & 6.1 & 1.0 & 0.0 & 2.13 \\
\hline $\begin{array}{l}T=400 \mathrm{~K}(\text { ab initio }) \\
\text { Pure water }\end{array}$ & 0.1 & 15.5 & 51.4 & \multicolumn{4}{|c|}{ Pure water } & 2.19 \\
\hline Bulk water (shell model) & 0.2 & 2.1 & 10.6 & 27.2 & 34.2 & 20.0 & 5.8 & 3.79 \\
\hline Bulk water (ab initio MD) & & & & & & & & $3.31-3.84^{c}$ \\
\hline Bulk water (TIP3P) & 0.2 & 0.8 & 7.1 & 28.9 & 52.3 & 10.3 & 0.5 & $3.65^{b}$ \\
\hline
\end{tabular}

the potential parameters we are using, is consistent with the experimental value of $-1314 \mathrm{~kJ} \mathrm{~mol}^{-1} .85$

To summarize, the structural properties of bulk water and water with a calcium ion and a calcium-carbonate complex, obtained using the shell model potential, are generally in very good agreement with ab initio results for the same systems and experimental values. Furthermore, phase transitions of liquid water to ice-like structure were only observed at simulation temperatures close to actual freezing for the system size in this study.

\section{Determining the water structure at the calcite surface}

Calcium and carbonate ions situated within the flat face are referred to here as face sites. At the calcite $\{10 \overline{1} 4\}$ surface, steps occur that have either an acute or obtuse angle to the surface. ${ }^{26}$ We therefore refer to ions positioned in step edges as either acute or obtuse edge sites. Likewise, corner sites are classified according to the structure of the edges they terminate. For example, an acute $\mathrm{Ca}$ corner site is a calcium ion positioned where two acute edges meet. Note that both $\mathrm{CO}_{3}$ corner sites terminate one acute and one obtuse edge each. The results for acute and obtuse edge sites represent those flanking the etch pit and the growth island (Fig. 2) unless stated otherwise.

Distances between surface calcium atoms ( $\equiv \mathrm{Ca}$ ) and the oxygen ions in the coordinating water molecules $\left(\mathrm{O}_{\text {water }}\right)$ were extracted from the MD trajectories, as averaged over 3100 configurations sampled over a nanosecond of the production run. To distinguish between the structurally different surface sites, each of the calcium and carbonate sites had been labelled differently: e.g. a calcium situated at a kink site was given a different label from a calcium at an acute or obtuse step edge or within a crystal face. The average distance of the first water layer perpendicular to the calcium carbonate plane was obtained by geometrical correction of the $\equiv \mathrm{Ca}-\mathrm{O}_{\text {water }}$ distance for its average angle relative to this plane.

The number of hydrogen-bonds between the water molecules coordinated to the surface sites and the surrounding water molecules were also extracted from the MD trajectories. In particular, to determine the existence of an $\mathrm{H}$-bond between two water molecules we have used the following geometrical criteria: (i) the donor-acceptor $\mathrm{O}_{\mathrm{w}} \cdots \mathrm{O}_{\mathrm{w}}$ distance is less than $3.5 \AA$; (ii) the donor-acceptor $\mathrm{H}_{\mathrm{w}} \cdots \mathrm{O}_{\mathrm{w}}$ distance is less than $2.45 \AA$; (iii) the hydrogen-donor-acceptor angle is less than $45^{\circ}{ }^{82,86}$ To the authors' knowledge, there are no configurational criteria for $\mathrm{H}$-bonding between water and oxygen atoms with carbonate surface groups. We have therefore adopted Gupta and Chandra's ${ }^{86}$ criteria for H-bonds between water and formic acid to determine the existence of a $\mathrm{H}$-bond between surface carbonate groups and water molecules: (i) the donor-acceptor $\mathrm{O}_{\mathrm{w}} \cdots \mathrm{O}_{\mathrm{c}}$ distance is less than $3.3 \AA$; (ii) the donor-acceptor $\mathrm{H}_{\mathrm{w}} \cdots \mathrm{O}_{\mathrm{c}}$ distance is less than $2.47 \AA$; (iii) the hydrogen-donor-acceptor angle is less than $45^{\circ}$.

\section{CD-MUSIC approach}

Recently, the CD-MUSIC formalism has been used to develop a surface chemical model for calcite. ${ }^{19}$ In summary, the proton affinity of a surface group is calculated from bond valence principles using the following empirical relationship: ${ }^{1}$

$$
\log K=-A\left(\sum_{j} s_{j}+V\right)
$$

where $A$ is a constant equal to 19.8 , obtained from empirically fitting eqn (1) to proton affinity constants of metal-hydroxyl complexes, $V$ is the valence of the surface oxygen $(V=-2)$, and $\sum_{j} s_{j}$ is the sum of valence bonds with the nearest neighbours, expressed in valence units (v.u.):

$$
\sum_{j} s_{j}=\sum_{i} s_{\mathrm{Me}_{i}}+m s_{\mathrm{H}}+n\left(1-s_{\mathrm{H}}\right)
$$

where $\sum_{i} s_{\mathrm{Me}_{i}}$ is the valence contribution of all the cations $\left(\mathrm{Me}_{i}\right)$ surrounding the oxygen atom, either calcium or carbon ions in the case of calcite. The last two terms in eqn (2) are related to water interacting with the surface: $m$ and $n$ are the numbers of donating $(\equiv \mathrm{O}-\mathrm{H})$ and accepting $(\equiv \mathrm{O} \cdots \mathrm{H})$ hydrogen-bonds. $s_{\mathrm{H}}$ is the valence bond of a donating 
Table 3 Distribution of the number of hydrogen-bonds for oxygen within surface carbonate groups at structurally different positions and for oxygen within aqueous carbonate. Temperature is $300 \mathrm{~K}$ unless stated otherwise. The values given are percentages of oxygen atoms with the given number of hydrogen-bonds ${ }^{86}$

\begin{tabular}{|c|c|c|c|c|c|c|c|c|c|}
\hline \multirow[b]{2}{*}{$\equiv \mathrm{O}$ site position } & \multicolumn{7}{|c|}{ Number of hydrogen-bonds } & \multirow[b]{2}{*}{ Average } & \multirow[b]{2}{*}{ Corrected average } \\
\hline & $0(\%)$ & $1(\%)$ & $2(\%)$ & $3(\%)$ & $4(\%)$ & $5(\%)$ & $6(\%)$ & & \\
\hline Face (A) & 34.4 & 55.6 & 9.8 & 0.2 & 0.0 & 0.0 & 0.0 & 0.73 & 1.23 \\
\hline Face $(\mathrm{X})$ & 60.9 & 34.2 & 4.8 & 0.1 & 0.0 & 0.0 & 0.0 & 0.30 & \\
\hline Face (B) & 51.9 & 42.1 & 5.9 & 0.1 & 0.0 & 0.0 & 0.0 & 0.20 & \\
\hline Acute edge (A) & 21.1 & 44.9 & 24.9 & 7.5 & 1.5 & 0.1 & 0.0 & 1.29 & 1.29 \\
\hline Acute edge (X) & 33.9 & 40.1 & 20.1 & 5.5 & 0.4 & 0.0 & 0.0 & 0.95 & 1.37 \\
\hline Acute edge (B) & 48.0 & 46.8 & 4.9 & 0.2 & 0.0 & 0.0 & 0.0 & 0.42 & \\
\hline Obtuse edge (A) & 34.9 & 39.2 & 15.6 & 7.7 & 2.6 & 0.2 & 0.0 & 1.02 & 1.32 \\
\hline Obtuse edge (X) & 17.2 & 52.9 & 22.3 & 6.6 & 0.9 & 0.0 & 0.0 & 1.34 & 1.34 \\
\hline Obtuse edge (B) & 62.1 & 32.9 & 4.8 & 0.2 & 0.0 & 0.0 & 0.0 & 0.30 & \\
\hline Corner (A) & 21.4 & 50.4 & 23.2 & 4.7 & 0.4 & 0.0 & 0.0 & 1.53 & 1.53 \\
\hline Corner (X) & 19.2 & 42.0 & 31.6 & 6.7 & 0.6 & 0.0 & 0.0 & 1.79 & 1.79 \\
\hline Corner (B) & 23.9 & 43.8 & 25.6 & 6.0 & 0.6 & 0.1 & 0.0 & 0.75 & 0.75 \\
\hline \multicolumn{10}{|l|}{$\mathrm{O}$ of $\mathrm{CaCO}_{3}$ in water } \\
\hline$T=300 \mathrm{~K}$ (shell model $)$ & 4.8 & 26.7 & 28.9 & 21.7 & 9.8 & 5.7 & 2.5 & 3.58 & \\
\hline$T=320 \mathrm{~K}$ (shell model) & 6.0 & 28.9 & 28.4 & 19.7 & 9.5 & 5.3 & 2.3 & 3.54 & \\
\hline$T=340 \mathrm{~K}$ (shell model) & 12.9 & 26.7 & 25.8 & 18.3 & 8.9 & 8.9 & 5.2 & 3.47 & \\
\hline$T=400 \mathrm{~K}$ (shell model) & 10.9 & 30.0 & 27.7 & 16.5 & 8.6 & 4.8 & 1.6 & 3.25 & \\
\hline$T=400 \mathrm{~K}(\mathrm{CP}-\mathrm{MD})^{a, b}$ & 0.5 & 36.5 & 41.5 & 20.1 & 1.4 & 0.0 & 0.0 & 1.86 & \\
\hline$T=400 \mathrm{~K}(\mathrm{CP}-\mathrm{MD})^{a, c}$ & 9.5 & 22.6 & 28.0 & 37.5 & 2.3 & 0.0 & 0.0 & 2.00 & \\
\hline
\end{tabular}

hydrogen-bond, $\left(1-S_{\mathrm{H}}\right)$ is the valence bond of an accepting hydrogen-bond. The value for $s_{\mathrm{H}}$ depends on the length of the $\mathrm{O}-\mathrm{H}$ bond and is an average of 0.75 v.u. (0.68 to 0.88 v.u. ${ }^{87}$ ) per $\mathrm{H}$. The contribution of the surrounding Me ions $\left(s_{\mathrm{Me}}\right)$ is calculated according to: ${ }^{88}$

$$
S_{\mathrm{Me}}=\mathrm{e}^{\frac{\left(R_{0}-R\right)}{b}}
$$

where $R$ is the distance of the calcium- $\mathrm{O}_{\mathrm{w}}$ or carbon-oxygen. $R_{0}$ is the element specific distance and $b$ is a constant $(0.37 \pm$ $0.05 \AA$ ); $R_{0}$ and $b$ have been empirically determined from fitting eqn (3) to the chemical connectivity in inorganic crystals. $^{88}$

The calcite values for $R_{\mathrm{Ca}-\mathrm{O}_{\mathrm{w}}}$ and $m+n$ were originally assumed to be equal for face, edge and corner sites. ${ }^{19}$ The value $2.45 \AA^{37}$ was adopted for the average $R_{\mathrm{Ca}-\mathrm{O}_{\mathrm{w}}}$ and the $m+n$ values were obtained from fitting experimental $\zeta$-potential data. From the classical MD simulations performed in the current study, the values for $R_{\mathrm{Ca}-\mathrm{O}_{\mathrm{w}}}$ and $m+n$ have been determined for structurally distinct sites.

Net proton charge for different groups of sites was determined by summation of the products of the concentration of the (de-)protonated surface sites and their charge. For obtuse corners, for example, the net proton charge $\sigma_{\mathrm{H}}$ is:

$$
\sigma_{\mathrm{H}}=\frac{2}{3}\left[\equiv_{\mathrm{oc}} \mathrm{CO}_{3} \mathrm{H}^{+2 / 3}\right]-\frac{1}{3}\left[\equiv_{\mathrm{oc}} \mathrm{CO}_{3}{ }^{-1 / 3}\right]+\frac{5}{3}\left[\equiv_{\mathrm{oc}} \mathrm{CO}_{3} \mathrm{H}_{2}{ }^{+5 / 3}\right]
$$

Any charge contribution by adsorbing or desorbing lattice ions is ignored in this calculation. Aqueous and surface speciation calculations were carried out with the Visual Minteq 3.0 software ${ }^{89}$ for equilibrium conditions between calcite and a $0.01 \mathrm{~mol} \mathrm{~L}^{-1} \mathrm{KCl}$ solution at $25{ }^{\circ} \mathrm{C}$. Thermodynamic data for the $\mathrm{CaCO}_{3}-\mathrm{CO}_{2}-\mathrm{H}_{2} \mathrm{O}$ systems were taken from Plummer and
Busenberg. ${ }^{90}$ Electrostatic corrections for surface reactions were performed using the Three Plane model. ${ }^{19}$

\section{Results and discussion}

The interfacial water shows significant ordering due to adsorption of water molecules to the surface, which results in a first layer of ordered water molecules roughly parallel to the (1014) surface at $\sim 2.41 \AA$ from surface calcium ions (see Table 1, Fig. 4a), with its hydrogen atoms primarily interacting with water molecules in the liquid and with carbonate oxygen ions. The next layer of water molecules at a distance of $\sim 3.5 \AA$ from surface carbon atoms is still more ordered than bulk water, owing to $\mathrm{H}$-bonding with adsorbed water molecules and surface carbonate groups. Overall, the first layer of water molecules is situated at $2.41 \AA$ (between 2.35 and $2.43 \AA$ ) above the calcium carbonate plane, in general agreement with experimental ${ }^{22,24,25}$ analysis (Table 1). The layering and orientation of the water molecules in the first and second layers are in general agreement with classical ${ }^{37,40}$ and $a b$ initio $^{52} \mathrm{MD}$ simulations of the calcite-water interface. The average number of $\mathrm{H}$-bonds per water molecule in the calcite-water interface observed here (Table 2) agrees well with those observed by Perry et al. ${ }^{39}$

\section{Water structure around surface calcium sites}

Radial distribution functions for water oxygen in the proximity of surface calcium ions expectedly show that, with increasing under-coordination of the surface calcium, the number of adsorbed oxygen atoms increases (Fig. 5a and b, Table 1). The calcium ions in obtuse edge sites show a slightly higher density of water molecules in their first coordination shell compared to $\mathrm{Ca}$ in acute edge sites, in agreement with previous MD simulation results. ${ }^{42,43}$ 


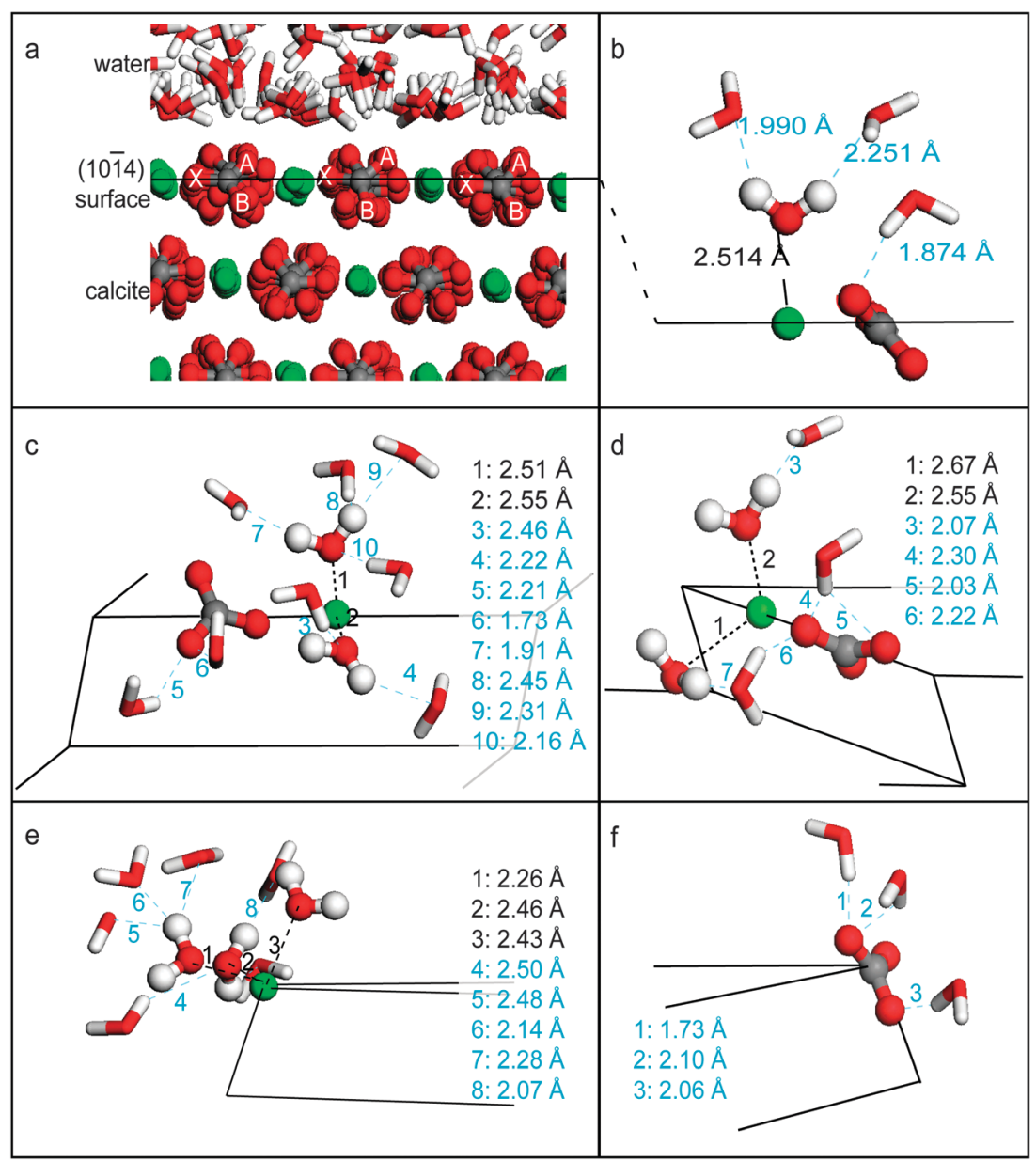

Fig. 4 (a) Simulation snapshot of the hydrated (1014) calcite surface. Oxygen atoms within the surface carbonate groups that point towards the aqueous solution are labelled A throughout the text; those oxygen atoms that are approximately level with the carbon atom in the crystal truncation plane are labelled X; those oxygen atoms that point into the bulk calcite lattice are labelled B. Snapshot of the interaction with water molecules of selected calcium and carbonate surface (b) face sites, (c) obtuse and (d) acute edges, and of a (e) calcium and (f) carbonate corner with water molecules. Black lines indicate surface topography; calcium indicated in green, oxygen in red, carbon in grey and hydrogen in white. The water molecule coordinated to surface calcium is given in ball-and-stick in (b-f), others are plotted as stick only.
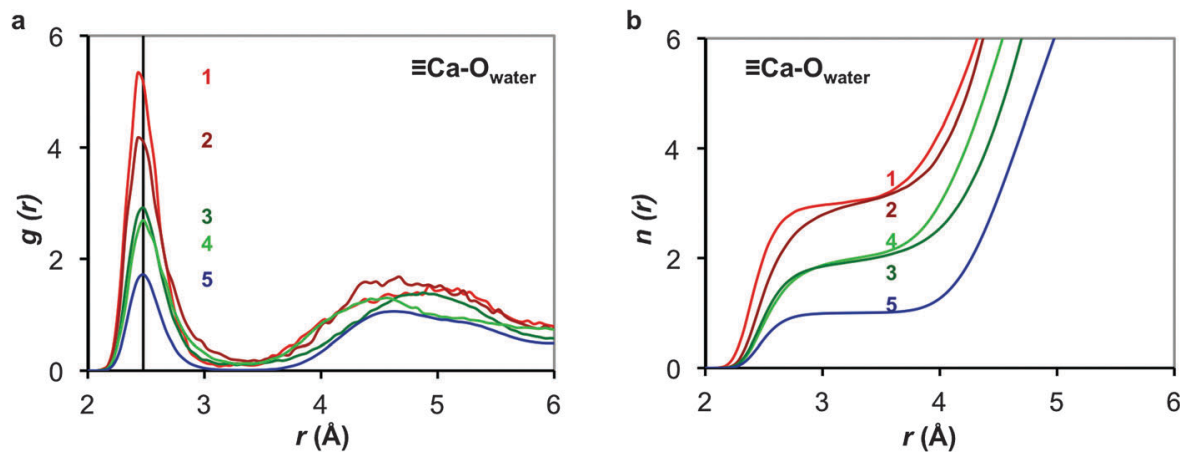

Fig. 5 Radial distribution functions (RDF) for the local environment in the water at structurally different calcium surface sites. (a) Atomic density $(g)$ variation in water oxygen with distance $(r)$ around the surface calcium sites. (c) Average number $(n)$ of water oxygen atoms within a sphere of radius $r$ around the surface calcium sites. $\equiv$ indicates surface site. Line numbers indicate the different surface calcium sites ( $\equiv \mathrm{Ca})$ : (1, bright red) one obtuse corner; (2, dark red) one acute corner; (3, dark green) six obtuse edge sites; (4, bright green) five acute edge sites; (5, blue) 91 face sites. For details and exceptions, see Tables 1 and 2.

Table 2 reports the distribution and average number of hydrogen-bonds $\left(n_{\mathrm{HB}}\right)$ between the water molecules coordinated to the surface calcium atoms and the surrounding water molecules. The number of $\mathrm{H}$-bonds for the water molecules coordinated to calcium atoms is reduced considerably from the number of $\mathrm{H}$-bonds obtained from the analysis of a molecular 
dynamics trajectory of bulk water, $n_{\mathrm{HB}}=3.8$. However, the effect of calcium site types (face, edge, corner) on the H-bonding network is, on the other hand, not significant. In fact, water molecules adsorbed to Ca surface atoms are involved on average in 2.1-2.3 H-bonds. The interaction between water molecules and $\mathrm{Ca}$ surface sites is illustrated in a series of close-up snapshots in Fig. 4. Fig. 4a shows the highly structured water at the interface between calcite and water. In Fig. $4 b$, only water molecules interacting with a $\mathrm{Ca}-$ and $\mathrm{CO}_{3}$ - surface site are highlighted, with the water molecule adsorbed to the Ca face site given as ball-and-stick (throughout all images), and adsorption indicated by the dashed black line. For this particular snapshot, two H-bonds are involved with the water molecule coordinated to the $\mathrm{Ca}$ face site. An example of the interaction between water molecules and neighbouring $\mathrm{Ca}$ in an obtuse edge is depicted in Fig. 4c. For this particular example, six H-bonds are formed per $\mathrm{Ca}$ edge site and its two adsorbed water molecules. In the example snapshot of an acute edge (Fig. 4d), two H-bonds are associated with per $\mathrm{Ca}$ edge site. The average $n_{\mathrm{HB}}$ extracted from the DL_POLY trajectory is $4.04-4.47$ per obtuse $\equiv \mathrm{Ca}\left(\mathrm{OH}_{2}\right)_{n}$ edge site and 4.32 per acute $\equiv \mathrm{Ca}\left(\mathrm{OH}_{2}\right)_{n}$ edge site. In Fig. $4 \mathrm{e}$, the interaction of water molecules adsorbed to an obtuse $\mathrm{Ca}$ corner with their surrounding water molecules is illustrated. The three adsorbed water molecules formed six $\mathrm{H}$-bonds in total with surrounding water molecules at the moment of this snapshot. The average $n_{\mathrm{HB}}$ obtained from the DL_POLY trajectory is 6.52 for obtuse $\equiv \mathrm{Ca}\left(\mathrm{OH}_{2}\right)_{n}$ corners and $\overline{6} .73$ for acute $\equiv \mathrm{Ca}\left(\mathrm{OH}_{2}\right)_{n}$ corners. Implications of these results for the differential affinity of various surface $\equiv \mathrm{Ca}\left(\mathrm{OH}_{2}\right)_{n}$ sites towards protons will be discussed below.

Freeman et $a .^{43}$ observed lower numbers of $\mathrm{H}$-bonds at the acute rather than obtuse step edge. Some of the disagreement with our observations might come from the potentials used for water (shell-model versus TIP3P) and the slightly different criteria used to define the existence of an $\mathrm{H}$-bond between two water molecules. Moreover, their configuration was quite different from ours. Since their aim was to investigate protein-step interactions, they chose to study vicinal faces: their acute steps are located on the vicinal $\{31.8\}$ surface and periodically repeat every $\sim 1 \mathrm{~nm}$; their obtuse steps are located on the vicinal $\{31.16\}$ surface and periodically repeat every $\sim 1.7 \mathrm{~nm}$. The difference in step density may have caused some of the relative differences in number of HBs they obtained. Moreover, on the acute-stepped surface, they observed clumping together of the water molecules in the first layer, leaving voids of zero water density on the surface and no formation of a continuous network in contrast to their obtuse-stepped surface. This phenomenon was explained to arise from the lack of a continuous Ca cation network in the $\{31.8\}$ surface, preventing the interaction with other water molecules within the first layer. Since a continuous Ca cation network does exist around the acute steps at the $\{10-14\}$ surface, and the typical separation between steps on rhombohedral calcite crystals grown in the laboratory is of the order of $100 \mathrm{~nm}$, our results are likely to be more indicative for the water structure around steps at the $\{10-14\}$ surface.

\section{Water structure around surface carbonate groups}

The variation in interaction between oxygen within carbonate surface groups and the surrounding water molecules can be viewed from two perspectives. Firstly, like calcium, the carbonate surface sites can be in face, edge or corner position. Secondly, there are oxygen ions that point out of the surface towards the water molecules ('type A' in Fig. 4a); ones that are approximately level with carbon in the crystal truncation plane ('type $\mathrm{X}$ ', Fig. 4a); and ones that are pointing in towards the bulk crystal ('type B', Fig. 4a). During equilibration and, to a lesser extent, over the course of the production run, some carbonate surface groups have rotated, for example turning type B oxygen into an $\mathrm{A}$ or $\mathrm{X}$ position. This rotation was observed to be most significant for growth-island corners, and decreases for edge sites and face sites, with face sites showing only minor rotation during equilibration and none during production. This rotation caused the counter-intuitive interaction to occur of type B oxygen in face and edge sites with water.

Table 3 reports the distribution and average number of $\mathrm{H}$-bonds between oxygen atoms within surface carbonate groups and the surrounding water molecules, determined according to the configurational criteria defined in Section 2. The rightmost column lists the average number of $\mathrm{H}$ bonds for the different surface oxygens, corrected for carbonate group rotation. The number of $\mathrm{H}$-bonds with type A oxygen increases from 1.23 for face sites to 1.53 for corners. Type $\mathrm{X}$ oxygen has $n_{\mathrm{HB}}$ values of around 1.35 for edge sites and 1.79 for corner sites, while cornersite oxygen type $\mathrm{B}$ has on average $0.75 \mathrm{H}$ bonds.

Fig. 6 illustrates the average variation in water hydrogen $\left(\mathrm{H}_{\text {water }}\right)$ density near the different types of carbonate oxygen at different surface positions as a Radial Distribution Function (RDF). For carbonate face sites, only type A oxygen atoms have a clear first shell with $\mathrm{H}_{\text {water }}$ (Fig. 6a). In contrast, the RDF for carbonate sites at acute edges clearly shows that both type $\mathrm{A}$ and $\mathrm{X}$ oxygen have a higher $\mathrm{H}$-bond density in $\mathrm{H}_{\text {water }}$ (Fig. 6b), and carbonate groups in obtuse edges have similar first shells with $\mathrm{H}_{\text {water }}$ for all three of their oxygen atoms (Fig. 6c). This result agrees with recent DFT simulations of the adsorption of one water molecule on the stepped (1014) surface, where the adsorption energy on the acute step was $0.43 \mathrm{eV}$ lower than on the obtuse step. ${ }^{52}$ Carbonate corner sites also show a clear first shell with $\mathrm{H}_{\text {water }}$ around all three of their oxygen atoms, albeit more strongly through types $\mathrm{A}$ and $\mathrm{X}$ than through type B (Fig. 6d). Note that, in Fig. 6, not all $\mathrm{H}_{\text {water }}$ in the first shell of carbonate oxygens $(r<2.45 \AA)$ comply with the configurational criteria for hydrogen-bonds ${ }^{86}$ and the RDF plots could not be corrected for any carbonate group rotation.

The interaction between water molecules and oxygen in a carbonate face site is illustrated in Fig. 4b. The carbonate face site in this snapshot interacts with one water molecule through their type A oxygen. Examples of $\mathrm{H}$-bonds with surface oxygen in an obtuse and acute edge are depicted in Fig. $4 \mathrm{c}$ and $\mathrm{d}$, respectively. In these particular examples, the surface carbonate

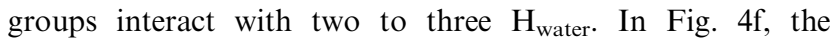
interaction of an obtuse $\mathrm{CO}_{3}$ corner with its $\mathrm{H}$-bonding water molecules is illustrated. In this snapshot, all three oxygen atoms form $\mathrm{H}$-bonds with four surrounding water molecules.

\section{Implications for surface site reactivity}

With the variation in hydrogen-bonding between interfacial water and the calcite surface groups quantified, eqn (1) to (3) 
a

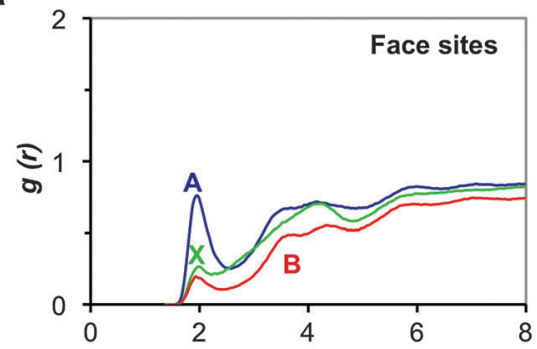

C

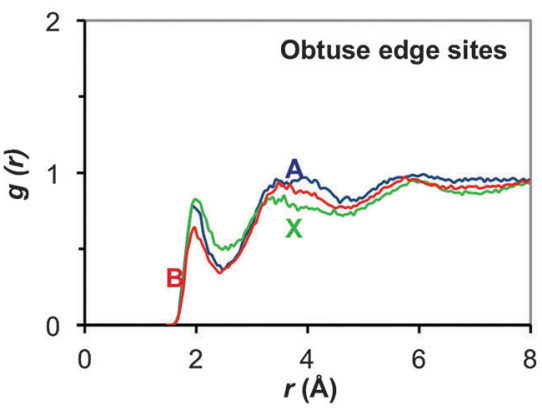

b

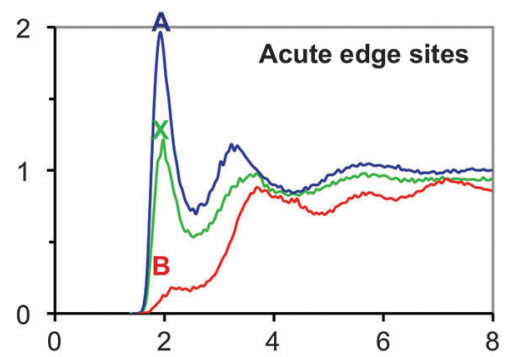

d

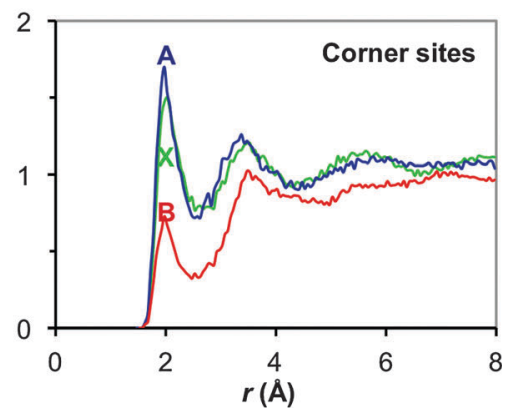

Fig. 6 RDF for water hydrogen atoms in the local environment of the oxygen atoms within surface carbonate groups (a) in 91 sites within a flat face; (b) in 11 sites at acute step edges; (c) in 7 sites at obtuse step edges and (d) in 2 corner sites of a growth island. In blue, the RDF for type 'A' oxygen atom, in green for type ' $\mathrm{X}$ ' and in red for type 'B' oxygen within surface carbonate groups (Fig. 4a).

Table 4 CD-MUSIC model tableau describing calcite surface chemistry; $x$ can either represent face (f), acute edge (ae), obtuse edge (oe), acute corner (ac), obtuse corner (oc) or obtuse/acute (c) corner; $y$ and $z$ represents formal charge; $y=-{ }^{2} / 3$ for face, $-1 / 3$ for edge and 0 for corner sites; $z=+{ }^{2} / 3$ for face, $+{ }^{1} / 3$ for edge and 0 for corner sites; $\Delta z_{0}$ and $\Delta z_{1}$ are Boltzmann parameters describing the charge distribution between the different planes across the mineral-solution interface ${ }^{1}$

\begin{tabular}{|c|c|c|c|c|c|c|c|c|c|c|c|c|c|}
\hline \multirow[b]{2}{*}{ Ca species } & \multicolumn{5}{|c|}{ Components } & \multicolumn{3}{|c|}{2008 values } & \multicolumn{5}{|c|}{ Refined values } \\
\hline & $\mathrm{H}^{+}$ & $\mathrm{OH}^{-}$ & $\mathrm{Ca}^{2+}$ & $\mathrm{CO}_{3}{ }^{2-}$ & $\equiv{ }_{x} \mathrm{CaOH}^{y}$ & $\log K_{\text {old }}$ & $\Delta z_{0}$ & $\Delta z_{1}$ & $\log K_{\mathrm{f}}^{e}$ & $\log K_{\mathrm{ae}}{ }^{e}$ & $\log K_{\mathrm{oe}}{ }^{e}$ & $\log K_{\mathrm{ac}}{ }^{e}$ & $\log K_{\mathrm{oc}}{ }^{e}$ \\
\hline $\begin{array}{l}\equiv{ }_{x} \mathrm{CaOH}_{2}{ }^{y+1} \\
{ }_{x}{ }_{x} \mathrm{CaO}^{y-1} \\
\equiv_{x} \mathrm{CaHCO}_{3}{ }^{y} \\
{ }_{x}{ }_{x} \mathrm{CaCO}_{3}{ }^{y-1}\end{array}$ & $\begin{array}{l}1 \\
-1 \\
1\end{array}$ & $\begin{array}{l}-1 \\
-1\end{array}$ & & $\begin{array}{l}1 \\
1\end{array}$ & $\begin{array}{l}1 \\
1 \\
1 \\
1\end{array}$ & $\begin{array}{l}12.85^{a} \\
-24.73^{a} \\
10.15^{c} \\
1.55^{c}\end{array}$ & $\begin{array}{l}+1 \\
-1 \\
0.6 \\
0.6\end{array}$ & $\begin{array}{l}0 \\
0 \\
-0.6 \\
-1.6\end{array}$ & $\begin{array}{l}13.42 \\
-25.30 \\
10.15^{c} \\
1.55^{c}\end{array}$ & $\begin{array}{l}14.15 \\
-26.03 \\
10.15^{c} \\
1.55^{c}\end{array}$ & $\begin{array}{l}13.10 \\
-24.98 \\
10.15^{c} \\
1.55^{c}\end{array}$ & $\begin{array}{l}13.57 \\
-25.45 \\
10.15^{c} \\
1.55^{c}\end{array}$ & $\begin{array}{l}13.70 \\
-25.58 \\
10.15^{c} \\
1.55^{c}\end{array}$ \\
\hline $\begin{array}{l}\mathrm{CO}_{3} \text { species } \\
\equiv{ }_{x} \mathrm{CO}_{3}{ }^{z-1}\end{array}$ & $\begin{array}{l}\mathrm{H}^{+} \\
-1\end{array}$ & $\mathrm{OH}^{-}$ & $\mathrm{Ca}^{2+}$ & $\mathrm{CO}_{3}{ }^{2-}$ & $\equiv_{1}{ }_{x} \mathrm{CO}_{3} \mathrm{H}^{z}$ & $-3.58^{b}$ & -1 & 0 & $\begin{array}{l}\text { O type } \\
\text { A } \\
\text { X } \\
\text { B }\end{array}$ & $\begin{array}{l}\log K_{\mathrm{f}}^{e} \\
-1.19\end{array}$ & $\begin{array}{l}\log K_{\mathrm{ae}}^{e} \\
-0.95 \\
-0.64\end{array}$ & $\begin{array}{l}\log K_{\mathrm{oe}}^{e} \\
-0.83 \\
-0.75\end{array}$ & $\begin{array}{l}\log K_{\mathrm{c}}^{e} \\
0.00 \\
1.03 \\
-3.09\end{array}$ \\
\hline$\equiv{ }_{x} \mathrm{CO}_{3} \mathrm{H}_{2}{ }^{z+1}$ & -1 & & 1 & & 1 & $-8.30^{b, d}$ & +1 & $+2^{e}$ & $\begin{array}{l}\text { A } \\
\text { X } \\
\text { B } \\
\text { A,X,B }\end{array}$ & -10.69 & $\begin{array}{l}-10.93 \\
-11.24 \\
-2.8^{c}\end{array}$ & $\begin{array}{l}-11.05 \\
-11.13 \\
-2.8^{c}\end{array}$ & $\begin{array}{l}-11.88 \\
-12.91 \\
-8.79 \\
-2.8^{c}\end{array}$ \\
\hline
\end{tabular}

${ }^{a}$ Previous equilibrium constants were obtained using a total of 2.4 and ${ }^{b} 2.2$ accepting and donating hydrogen bridges, $\equiv \mathrm{Ca}-\mathrm{O}_{\text {water }}=2.45 \AA$ and $\equiv \mathrm{C}-\mathrm{O}=1.27 \AA .{ }^{19}{ }^{c}$ From Van Cappellen et al. ${ }^{17 d}$ Corner only. ${ }^{e}$ Refined constants were calculated using eqn (1)-(3), site specific $\equiv \mathrm{Ca}-\mathrm{O}_{\text {water }}$ and number of $\mathrm{H}$-bonds as listed in Tables $1-3$ for $300 \mathrm{~K}$ and $\equiv \mathrm{C}-\mathrm{O}=1.195 \AA$.

can now be used to calculate the variation in affinity of the different surface groups for protons. Table 4 compares the resulting revised protonation constants with the previously published constants. Note that each water molecule that is adsorbed to a surface calcium ion is treated as one surface $\equiv{ }_{x} \mathrm{Ca}\left(\mathrm{OH}_{2}\right)^{y+1}$ site. Adsorption constants for calcium, carbonate and bicarbonate are also listed, for completeness, although these were not refined in the present study. $\ddagger$

\footnotetext{
$\ddagger$ Note that these values need to be revised to obtain agreement of the
} revised model with measured surface potentials.
The refined protonation constants for surface calcium sites deviate slightly from the previously published values and vary up to one order of magnitude between the structurally different sites. The slight variation in the number of HBs for structurally different calcium sites translates into nonnegligible variation in proton affinities. The obtuse edge site $\equiv{ }_{\mathrm{oe}} \mathrm{CaOH}_{2}{ }^{+2 / 3}$ releases its proton most readily of all surface calcium sites. Contrastingly, the acute edge site $\equiv{ }_{\mathrm{ae}} \mathrm{CaOH}_{2}{ }^{+2 / 3}$ is least likely to deprotonate; corners and face sites have intermediate protonation affinities. This behaviour is illustrated in Fig. 7, where the lines with positive slopes plot the concentration of singly deprotonated calcium surface sites. 


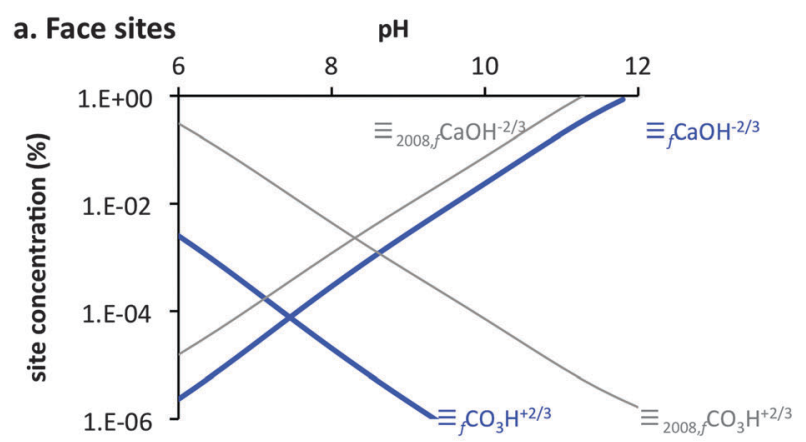

\section{b. Edge sites}

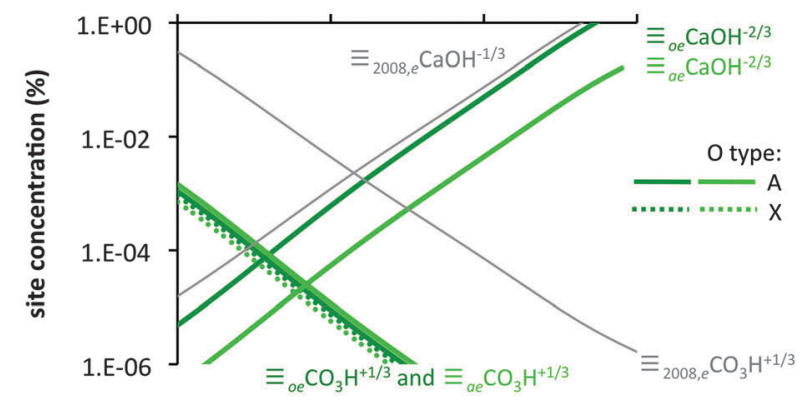

\section{c. Corner sites}

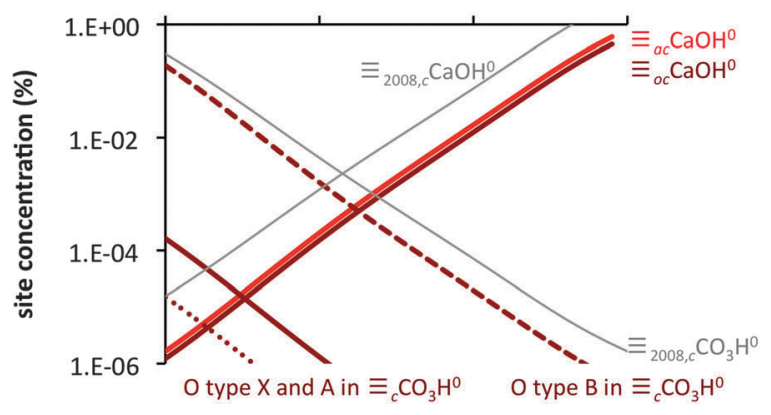

Fig. 7 Effect of refined protonation constants (Table 4) on surface speciation, illustrated for $\equiv{ }_{x} \mathrm{CaOH}^{y}$ and $\equiv{ }_{x} \mathrm{CO}_{3} \mathrm{H}^{z}$ species at (a) face, (b) edge and (c) corner sites compared to surface speciation from Wolthers et al. ${ }^{19}$ For all plots, sorbed lattice ions are not plotted and equilibrium between calcite and a $0.01 \mathrm{~mol} \mathrm{~L}^{-1} \mathrm{KCl}$ solution was assumed.

The refined protonation constants for surface carbonate groups show a strong deviation from the previously published values (Table 4), due to the lower number of HBs observed in the simulation (Table 3) compared to the fitted number of HBs of 2.2 as an average for all surface carbonate groups. ${ }^{19}$ The refined surface carbonate protonation constants for face and edge sites shown in Fig. 7a and b respectively, are comparable, while those for corner sites show a wide spread in values for the three different carbonate oxygens (Fig. 7c). Type B oxygen, which is most closely associated with the calcite bulk, is the least likely to be doubly protonated. Despite its low number of $\mathrm{HBs}$, it is closest in proton affinity to the previous value due to the shorter $\mathrm{C}-\mathrm{O}$ bond length used in eqn (3): in the previous model, a value of $1.27 \AA$ was used, while currently the $1.195 \AA$ observed in the simulation results was used. This shorter $\mathrm{C}-\mathrm{O}$

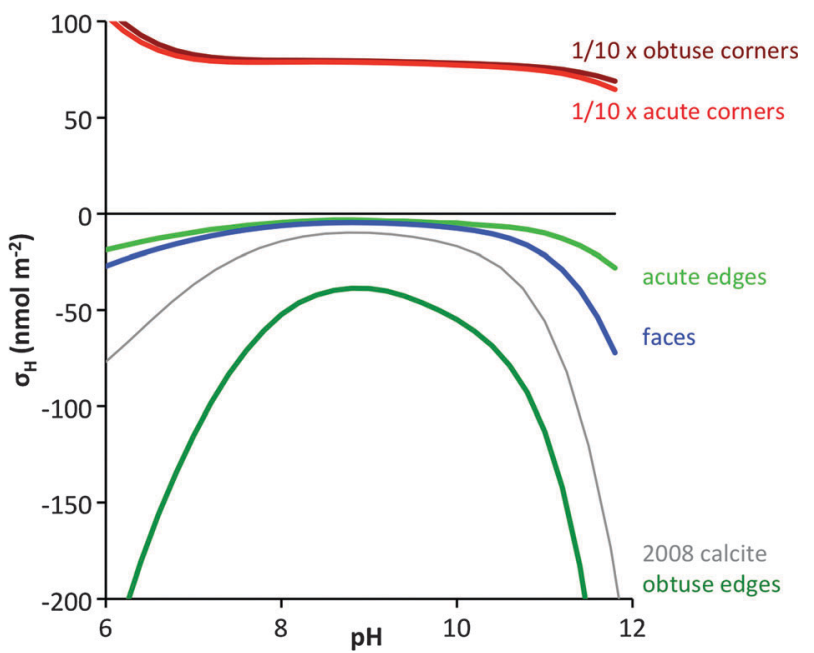

Fig. 8 Net proton charge $\sigma_{\mathrm{H}}$ (eqn (4)) for the different groups of surface sites versus $\mathrm{pH}$, scaled assuming all types are present at the same surface density and in the case of corners, divided by ten for illustration purposes. Net proton charge for the calcite surface according to the Wolthers et al. ${ }^{19} 2008$ model is plotted in grey for comparison. Note that charge contribution by sorbing lattice ions was ignored.

bond cancels the effect of the HBs when calculating the proton affinities.

Another new insight gained from the MD simulations is the increase in the number of reactive sites. In previous models describing the surface reactivity of calcite using the Constant Capacitance model, ${ }^{17,18}$ it has generally been assumed that only one oxygen atom per carbonate group interacts with the aqueous solution. Recently, Wolthers et al. ${ }^{19}$ suggested that carbonate corner sites interact with the aqueous solution through two oxygen atoms. The current results clearly show that carbonate surface groups interact through up to three oxygen atoms with the surrounding water molecules. Similarly, assuming one $\equiv{ }_{x} \mathrm{Ca}\left(\mathrm{OH}_{2}\right)^{y+1}$ site per surface calcium will lead to an underestimation of the number of reactive sites, given that up to three water molecules may be coordinated to one surface calcium. This implies that the density of reactive surface sites can be far higher than the $4.9 \equiv{ }_{x} \mathrm{Ca}\left(\mathrm{OH}_{2}\right)^{y+1}$ sites and $4.9 \equiv{ }_{x} \mathrm{CO}_{3}{ }^{z-1}$ per $\mathrm{nm}^{-2}$ commonly assumed based on crystallographical site densities, ${ }^{17}$ and that reactive surface site density is directly related to surface topography.

In order to illustrate the impact of the proton affinity refinement on surface charging behaviour of structurally different sites, the net proton charge (eqn (4)) has been plotted in Fig. 8 for various surfaces that were assumed to exist solely of one type of surface structure. For example, for the obtuse edge curve it was assumed that all calcite surface groups obey the protonation constants for obtuse edge sites. Interestingly, the surface proton charges in Fig. 8 show that corners are overall positively charged, while flat faces and edges are overall negatively charged. For comparison, the net proton charge from the previous calcite CD-MUSIC model is plotted as well (grey line in Fig. 8), with charges intermediate between the refined flat faces and obtuse edges. This suggests that the overall surface protonation for a calcite surface existing of some ratio of flat faces, edges and corners, is likely to be 
slightly higher than the previously published calcite models. Note that this outcome may change when lattice ion sorption constants are refined in order to fit experimental $\zeta$-potential data.

The strikingly higher negative charge on the obtuse compared to acute edges is caused by the subtle differences in hydrogen bonding with, in particular, the $\equiv_{x} \mathrm{Ca}\left(\mathrm{OH}_{2}\right)^{y+1}$ sites. Adsorption and incorporation of trace metals and (oxy)anions have previously been shown to occur differentially, with different ions preferring either acute or obtuse edge sites. ${ }^{26,91,92}$ This behaviour has thus far been related to the difference in geometry and coordination of the acute versus obtuse edge sites. ${ }^{26}$ Our quantitative results show that the chemical reactivity of the two edges is markedly distinct.

The differential charging behaviour of the obtuse and acute edges with $\mathrm{pH}$ is a likely cause for the selectivity of these edges towards certain metals and (oxy-)anions, together with the variation in geometry and coordination. Also, the distinct charging behaviour of faces and edges versus corners will control where constituent ions and contaminants will adsorb onto the surface. Clearly, the surface topography will affect the average calcite surface reactivity observed in macroscopic experiments such as bulk surface potential measurements and adsorption experiments. Furthermore, kink sites and edge sites are known to play a crucial role in calcite growth ${ }^{10,93}$ and dissolution ${ }^{35,56,94,95}$ kinetics. The detailed insight into the variation of interaction between water molecules and structurally different calcite surface sites obtained in the present study allows for the quantification of variations in the reactivity of the structurally different sites and morphologically different surfaces.

\section{Conclusions}

Classical molecular dynamic simulations of calcite $\{10 \overline{1} 4\}$ surfaces with an explicit etch pit and growth island show that the structure of the water surrounding different surface sites varies significantly:

- While thus far it has been assumed in many surface complexation models that each surface calcium ion and carbonate group represents a single surface site, our results clearly show that this assumption may lead to a strong underestimation of the total number of reactive surface sites.

- Surface calcium ions may adsorb up to three water molecules, depending on surface position (face, edge or corner). Since each adsorbed water molecule represents a surface reactive site, a single surface calcium ion may account for up to three surface reactive sites, each forming on average 2.2 hydrogenbonds with neighbouring water molecules.

- Surface carbonate groups may interact with surrounding water molecules through all three of their oxygen atoms, depending on their position in the surface (face, edge or corner). This behaviour is partially due to carbonate rotation, the extent of which again depends on the site. As a result, the surface carbonate groups may also account for up to three surface reactive sites, with the number of hydrogen-bonds increasing as the coordination of the carbonate group decreases.

- The subtle variations in the number of hydrogen-bonds observed for structurally distinct surface sites translate into significant differences in charging behaviour of the structurally different sites:

othe net proton charge (as defined in eqn (4)) of obtuse edges is generally ten times more negative than those of acute edges and face sites;

- corner sites show an overall strongly positive net proton charge.

- The strong variation in charging behaviour at the obtuse and acute edges can also, at least in part, explain their previously observed differential uptake of contaminants.

- The overall calcite mineral-surface reactivity is controlled by its topography.

This paper shows how molecular dynamics simulations can be used to develop and refine macroscopic complexation models that are able to differentiate the acid-base and electrical charging properties of distinct surface sites, and are therefore capable of describing the reactivity of more realistic metal carbonate minerals.

Future work will focus on the differential incorporation of impurity ions at the different surface sites. As a number of cations commonly observed in calcium carbonates, e.g. $\mathrm{Mg}$ and $\mathrm{Sr}$, are used as proxies in palaeoclimatological investigations, quantitative understanding of their uptake and distribution within the mineral is of significant interest.

\section{Acknowledgements}

We would like to thank Jack Middelburg for insightful discussions. Via our membership of the UK's HPC Materials Chemistry Consortium, which is funded by EPSRC (EP/ F067496), this work made use of the facilities of HECToR, the UK's national high-performance computing service, which is provided by UoE HPCx Ltd at the University of Edinburgh, Cray Inc. and NAG Ltd, and funded by the Office of Science and Technology through EPSRC's High End Computing Programme. A UK Royal Society International Joint Project and a British Council Partnership Programme in Science financially supported this work. Financial support to MW is acknowledged from the Netherlands Organisation for Scientific Research (NWO) through a VENI fellowship \#863.06.006 and from the Darwin Centre for Biogeosciences. Financial support to DDT is acknowledged from the UK's Royal Society through an Industry Fellowship.

\section{References}

1 T. Hiemstra and W. H. Van Riemsdijk, J. Colloid Interface Sci., 1996, 179, 488-508.

2 H. A. Lowenstam and S. Weiner, On Biomineralization, Oxford University Press, 1989.

3 J. W. Morse, A. J. Andersson and F. T. Mackenzie, Geochim. Cosmochim. Acta, 2006, 70, 5814-5830.

4 E. A. Boyle, Earth Planet. Sci. Lett., 1981, 53, 11-35.

5 R. J. Reeder, M. Nugent, C. D Tait, D. E Morris, S. M. Heald, K. M. Beck, W. P. Hess and A. Lanzirotti, Geochim. Cosmochim. Acta, 2001, 65, 3491-3503.

6 D. Archer and E. Maier-Reimer, Nature, 1994, 367, 260-263.

7 J. P. Kaszuba, D. R. Janecky and M. G. Snow, Appl. Geochem., 2003, 18, 1065-1080.

8 T. F. Xu, J. A. Apps and K. Pruess, J. Geophys. Res., [Solid Earth], 2003, 108, 2071.

9 G. Montes-Hernandez, F. Renard, N. Geoffroy, L. Charlet and J. Pironon, J. Cryst. Growth, 2007, 308, 228-236. 
10 H. H. Teng, P. M. Dove and J. J. DeYoreo, Geochim. Cosmochim. Acta, 2000, 64, 2255-2266.

11 M. Wolthers, G. Nehrke, J.-P. Gustafsson and P. Van Cappellen, Geochim. Cosmochim. Acta, 2012, 77, 121-134.

12 P. Raiteri and J. Gale, J. Am. Chem. Soc., 2010, 132, 17623-17634.

13 M. Xu, X. M. Hu, K. G. Knauss and S. R. Higgins, Geochim. Cosmochim. Acta, 2010, 74, 4285-4297.

14 O. S. Pokrovsky, S. V. Golubev, J. Schott and A. Castillo, Chem. Geol., 2009, 265, 20-32.

15 J. A. Davis, R. O. James and J. O. Leckie, J. Colloid Interface Sci., 1978, 63, 480-499.

16 R. N. J. Comans and J. J. Middelburg, Geochim. Cosmochim. Acta, 1989, 51, 2587-2591.

17 P. Van Cappellen, L. Charlet, W. Stumm and P. Wersin, Geochim. Cosmochim. Acta, 1993, 57, 3505-3518.

18 O. S. Pokrovsky and J. Schott, Environ. Sci. Technol., 2002, 36, 426-432.

19 M. Wolthers, L. Charlet and P. Van Cappellen, Am. J. Sci., 2008, 308, 905-941.

20 S. Mettler, M. Wolthers, L. Charlet and U. von Gunten, Geochim. Cosmochim. Acta, 2009, 73, 1826-1840.

21 A. Villegas-Jimenez, A. Mucci, O. Pokrovsky and J. Schott, Geochim. Cosmochim. Acta, 2009, 73, 4326-4345.

22 T. Hiemstra, P. Venema and W. H. Van Riemsdijk, J. Colloid Interface Sci., 1996, 184, 680-692.

23 P. Geissbühler, P. Fenter, E. DiMasi, G. Srajer, L. B. Sorensen and N. C. Sturchio, Surf. Sci., 2004, 573, 191-203.

24 F. Heberling, T. P. Trainor, J. Lützenkirchen, P. Eng, M. A. Denecke and D. Bosbach, J. Colloid Interface Sci., 2011, 354, 843-857.

25 P. Fenter, P. Geissbühler, E. Dimasi, G. Srajer, L. B. Sorensen and N. C. Sturchio, Geochim. Cosmochim. Acta, 2000, 64, 1221-1228.

26 J. Paquette and R. J. Reeder, Geochim. Cosmochim. Acta, 1995, 59, $735-749$.

27 C. A. Orme, A. Noy, A. Wierzbicki, M. T. McBride, M. Grantham, H. H. Teng, P. M. Dove and J. J. DeYoreo, Nature, 2001, 411, 775-779.

28 N. H. De Leeuw and S. C. Parker, J. Chem. Soc., Faraday Trans., 1997, 3, 467-475.

29 N. H. De Leeuw and S. C. Parker, J. Phys. Chem. B, 1998, 102, 2914-2922.

30 N. H. De Leeuw and S. C. Parker, Phys. Rev. B: Condens. Matter Mater. Phys., 1998, 58, 13901-13908.

31 J. O. Titiloye, N. H. De Leeuw and S. C. Parker, Geochim. Cosmochim. Acta, 1998, 62, 2637-2641.

32 K. Wright, R. T. Cygan and B. Slater, Phys. Chem. Chem. Phys., 2001, 3, 839-844.

33 K. Wright, R. T. Cygan and B. Slater, Geochim. Cosmochim. Acta, 2002, 66, 2541-2546.

34 N. H. De Leeuw, J. Phys. Chem. B, 2002, 106, 5241-5249.

35 A. C. Lasaga and A. Lüttge, Eur. J. Mineral., 2003, 15, 603-615.

36 R. T. Cygan, K. Wright, D. K. Fisler, J. D. Gale and B. Slater, Mol. Simul., 2002, 28, 475-495.

37 S. Kerisit, S. C. Parker and J. H. Harding, J. Phys. Chem. B, 2003, 107, 7676-7682.

38 A. L. Rohl, K. Wright and J. D. Gale, Am. Mineral., 2003, 88, 921-925.

39 T. D. Perry IV, R. T. Cygan and R. Mitchell, Geochim. Cosmochim. Acta, 2007, 71, 5876-5887.

40 S. Kerisit and S. C. Parker, J. Am. Chem. Soc., 2004, 126, 10152-10161.

41 N. H. De Leeuw and T. G. Cooper, Cryst. Growth Des., 2004, 4, 123-133.

42 D. Spagnoli, S. Kerisit and S. C. Parker, J. Cryst. Growth, 2006, 294, 103-110.

43 C. L. Freeman, J. H. Harding, D. Quigley and P. M. Rodger, Phys. Chem. Chem. Phys., 2012, 14, 7287-7295.

44 D. J. Cooke and J. A. Elliott, J. Phys. Chem., 2007, 127, 104706.

45 M. Yang, S. L. S. Stipp and J. H. Harding, Cryst. Growth Des., 2008, 8, 4066-4074.

46 P. Raiteri, J. D. Gale, D. Quigley and P. M. Rodger, J. Phys. Chem. C, 2010, 114, 5997-6010.

47 J. D. Gale, P. Raiteri and A. C. T. van Duin, Phys. Chem. Chem. Phys., 2011, 13, 16666-16679.

48 D. Quigley, C. L. Freeman, J. H. Harding and P. M. Rodger, J. Chem. Phys., 2011, 134, 044703.
49 C. L. Freeman, J. H. Harding, D. Quigley and P. M. Rodger, J. Phys. Chem. C, 2011, 115, 8175-8183.

50 A. Villegas-Jimenez, A. Mucci and M. A. Whitehead, Langmuir, 2009, 25, 6813-6824.

51 J. S. Lardge, D. M. Duffy, J. M. Gillan and M. Watkins, J. Phys. Chem. C, 2010, 114, 2664-2668.

52 J. S. Lardge, D. M. Duffy and M. J. Gillan, J. Phys. Chem. C, 2009, 113, 7207-7212.

53 D. Aquilano, M. Bruno, F. R. Massaro and M. Rubbo, Cryst. Growth Des., 2011, 11, 3985-3993.

54 S. Stipp and F. M. Hochella, Geochim. Cosmochim. Acta, 1991, 55, $1723-1736$.

55 I. N. Macinnis and S. L. Brantley, Geochim. Cosmochim. Acta, 1992, 56, 1113-1126.

56 Y. Liang, A. S. Lea, D. R. Baer and M. H. Engelhard, Surf. Sci., 1996, 351, 172-182.

57 N. H. De Leeuw, S. C. Parker and J. H. Harding, Phys. Rev. B. Condens. Matter Mater. Phys., 1999, 60, 13792.

58 R. Kristensen, S. L. S. Stipp and K. Refson, J. Chem. Phys., 2004, 121, 8511-8523.

59 N. H. De Leeuw, J. H. Harding and S. C. Parker, Mol. Simul., 2002, 28, 573-589.

60 E. Ruiz-Agudo, D. Di Tommaso, C. V. Putnis, N. H. de Leeuw and A. Putnis, Cryst. Growth Des., 2010, 10, 3022-3035.

61 M. Born and K. Huang, Dynamical Theory of Crystal Lattices, Oxford University Press, Oxford, 1954.

62 A. Pavese, M. Catti, S. C. Parker and A. Wall, Phys. Chem. Miner., 1996, 23, 89.

63 B. G. Dick and A. W. Overhauser, Phys. Rev., 1958, 112, 90.

64 P. J. Mitchell and D. Fincham, J. Phys.: Condens. Matter, 1993, 5, 1031.

65 R. Ferneyhough, D. Fincham, G. D. Price and M. J. Gillan, Model. Simul. Mater. Sci. Eng., 1994, 2, 1101-1110.

66 P. M. Oliver, S. C. Parker, R. G. Egdell and F. H. Jones, J. Chem. Soc., Faraday Trans., 1996, 92, 2049.

67 T. R. Forester and W. Smith, DL_POLY User Manual, CCLRC, Daresbury Laboratory, U.K., $199 \overline{5}$.

68 L. Verlet, Phys. Rev., 1967, 195, 98.

69 S. Nosé, J. Chem. Phys., 1984, 81, 511.

70 W. G. Hoover, Phys. Rev. A: At., Mol., Opt. Phys., 1985, 31, 1695.

71 W. A. Deer, R. A. Howie and J. Zussmann, Introduction to the Rock-forming Minerals, Longman, Harlow, U.K., 1992.

72 N. H. De Leeuw and S. C. Parker, J. Chem. Phys., 2000, 112, 4326-4333.

73 P. Giannozzi, S. Baroni, N. Bonini, M. Calandra, R. Car, C. Cavazzoni, D. Ceresoli, G. L. Chiarotti, M. Cococcioni, I. Dabo, A. Dal Corso, S. Fabris, G. Fratesi, S. de Gironcoli, R. Gebauer, U. Gerstmann, C. Gougoussis, A. Kokalj, M. Lazzeri, L. Martin-Samos, N. Marzari, F. Mauri, R. Mazzarello, S. Paolini, A. Pasquarello, L. Paulatto, C. Sbraccia, S. Scandolo, G. Sclauzero, A. P. Seitsonen, A. Smogunov, P. Umari and R. M. Wentzcovitch, J. Phys.: Condens. Matter, 2009, 21, 395502.

74 J. P. Perdew, K. Burke and M. Ernzerhof, Phys. Rev. Lett., 1996, 77, 3865.

75 D. Vanderbilt, Phys. Rev. B: Condens. Matter Mater. Phys., 1990, 41, 7892 .

76 http://www.physics.rutgers.edu/ dhv/uspp/.

77 G. J. Martyna, M. L. Klein and M. Tuckerman, J. Chem. Phys., 1992, 97, 2635.

78 E. Schwegler, J. C. Grossman, F. Gygi and G. Galli, J. Chem. Phys., 2004, 121, 5400; M. V. Fernández-Serra and E. Artacho, J. Chem. Phys., 2004, 121, 11136; P. H.-L. Sit and N. Marzari, J. Chem. Phys., 2005, 122, 204510.

79 P. J. van Maaren and D. van der Spoel, J. Phys. Chem. B, 2001, 105, 2618-2626.

80 K. Krynicki, C. D. Green and D. W. Sawyer, Discuss. Faraday Soc., 1978, 66, 199-208.

81 W. S. Price, H. Ide and Y. Arata, J. Phys. Chem. A, 1999, 103, $448-450$

82 A. Chandra, Phys. Rev. Lett., 2000, 85, 768-771.

83 J. A. Odutola and T. R. Dyke, Chem. Phys., 1980, 72, 5062.

84 I. Bako, J. Hutter and G. Palinkas, J. Chem. Phys., 2002, 117, 9838-9843.

85 Y. Marcus, J. Chem. Soc., Faraday Trans., 1991, 87, 2995-2999.

86 R. Gupta and A. Chandra, J. Chem. Phys., 2008, 128, 184506. 
87 J. R. Bargar, S. N. Towle, G. E. Brown Jr. and G. A. Parks, J. Colloid. Interface Sci., 1997, 185, 473-492.

88 I. D. Brown and D. Altermatt, Acta Crystallogr., Sect. B: Struct. Sci., 1985, 41, 244-247.

89 J. P. Gustafsson, Visual MINTEQ Version 3.0., Stockholm, Sweden, 2010.

90 L. N. Plummer and E. Busenberg, Geochim. Cosmochim. Acta, 1982, 46, 1011-1040.

91 E. J. Elzinga, C. D. Tait, R. J. Reeder, K. D. Rector, R. J. Donohoe and D. E. Morris, Geochim. Cosmochim. Acta, 2004, 68, 2437-2448.

92 V. G. Alexandratos, E. J. Elzinga and R. J. Reeder, Geochim. Cosmochim. Acta, 2007, 71, 4172-4187.
93 J. Bohr, R. A. Wogelius, P. M. Morris and S. L. S. Stipp, Geochim. Cosmochim. Acta, 2010, 74, 5985-5999.

94 A. J. Gratz, P. E. Hillner and P. K. Hansma, Geochim. Cosmochim. Acta, 1993, 57, 491-495.

95 S. L. S. Stipp, W. Gutmannsbauer and T. Lehmann, Am. Mineral., 1996, 81, 1-8.

96 F. Bruneval, D. Donadio and M. J. Parrinello, J. Phys. Chem. B, 2007, 111, 12219-12227.

97 C. L. Freeman, J. H. Harding, D. J. Cooke, J. A. Elliot, J. S. Lardge and D. M. Duffy, J. Phys. Chem. C, 2007, 111, 11943-11951.

98 T. Todorova, A. P. Seitsonen, J. Hutter, I.-F. Kuo and C. J. Mundy, J. Phys. Chem. B, 2006, 110, 3685-3691. 